lung function is impaired. It is unclear whether the presence of dyspnoea is associated with a worse course of SSc-ILD or with response to therapy.

Objectives: To investigate the rate of decline in FVC in patients with SSc-ILD in the SENSCIS trial in subgroups by patient-reported dyspnoea at baseline.

Methods: The SENSCIS trial enrolled patients with SSc-ILD with first non-Raynaud symptom within $\leq 7$ years before screening, extent of fibrotic ILD $\geq 10 \%$ on HRCT and FVC $\geq 40 \%$ predicted. Patients were randomised to receive nintedanib or placebo until the last patient reached week 52 . In post-hoc analyses, we analysed the rate of decline in FVC (mL/year) over 52 weeks in patients with and without dyspnoea at baseline based on the question about dyspnoea in the St. George's Respiratory Questionnaire (SGRQ). Patients who reported having shortness of breath "most days a week", "several days a week" or "a few days a month" (rather than "only with chest infection" or "not at all") over the last month were considered to have dyspnoea at baseline. A random slope and intercept model was used to assess the rate of decline in FVC (mL/year) and an interaction test was applied to assess potential heterogeneity in the treatment effect of nintedanib between the subgroups.

Results: Of 576 patients, $69.8 \%$ had dyspnoea at baseline. At baseline, in patients with and without dyspnoea, respectively, mean (SD) extent of fibrotic ILD on HRCT was 37.7 (21.7)\% and 31.6 (19.4)\%; mean (SD) FVC was 71.0 (16.3) and 76.5 (16.8) \% predicted; $50.7 \%$ and $44.8 \%$ were taking mycophenolate; $53.5 \%$ and $41.9 \%$ were taking corticosteroids. In the placebo group, the rate of decline in FVC (mL/year) was similar in patients with and without dyspnoea at baseline (Figure). The effect of nintedanib versus placebo on reducing the rate of decline in FVC (mL/year) was numerically more pronounced in patients without dyspnoea (difference: 79.8 [95\% Cl: 9.8, 149.7]) than with dyspnoea (difference: $25.7[-19.9,71.3])$, but the exploratory interaction $p$-value did not indicate heterogeneity in the treatment effect between subgroups $(p=0.20)$.

Conclusion: In the SENSCIS trial, patients with SSc-ILD who had dyspnoea at baseline had a numerically greater extent of fibrotic ILD on HRCT and numerically lower FVC \% predicted at baseline. The rate of decline in FVC in the placebo group was similar in patients with and without dyspnoea. Nintedanib had a numerically greater treatment effect in patients without dyspnoea. These data suggest that the presence of dyspnoea should not be used as a criterion for starting nintedanib in patients with SSc-ILD.

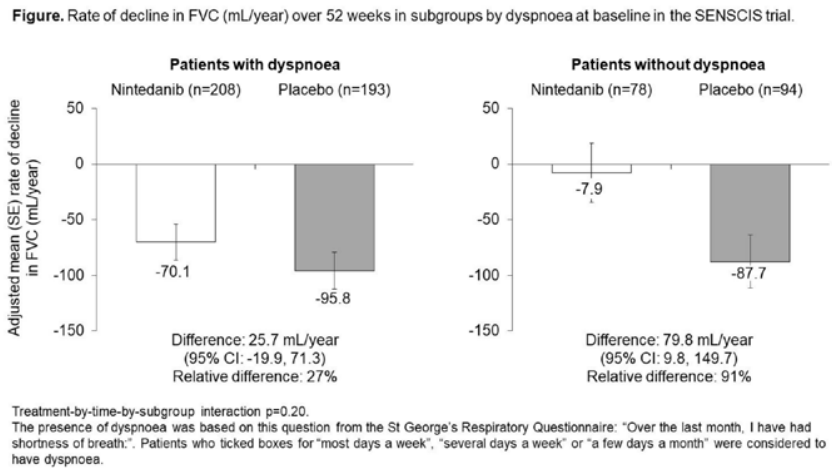

Acknowledgements: The SENSCIS trial was funded by Boehringer Ingelheim. Medical writing support was provided by Fleishman Hillard Fishburn, London, UK. The authors meet criteria for authorship as recommended by the International Committee of Medical Journal Editors (ICMJE).

Disclosure of Interests: Elizabeth Volkmann Consultant of: Boehringer Ingelheim, Grant/research support from: Corbus and Forbius, Michael Kreuter Speakers bureau: Boehringer Ingelheim, Consultant of: Boehringer Ingelheim, Grant/research support from: Boehringer Ingelheim and Roche, Anna-Maria Hoffmann-Vold Speakers bureau: Actelion, Boehringer Ingelheim, Lilly, Merck Sharp \& Dohme and Roche, Consultant of: Actelion, Arxx Therapeutics, Bayer, Boehringer Ingelheim, Lilly, Medscape, Merck Sharp \& Dohme and Roche, Grant/research support from: Boehringer Ingelheim, Marlies Wijsenbeek Speakers bureau: Boehringer Ingelheim (fees paid to institution) and Hoffmann-La Roche (fees paid to institution), Consultant of: Boehringer Ingelheim (fees paid to institution), Bristol-Myers Squibb (fees paid to institution), Galapagos NV (fees paid to institution), Hoffmann-La Roche (fees paid to institution), NeRRe Therapeutics (fees paid to institution), OncoArendi Therapeutics (fees paid to institution), Respivant Sciences (fees paid to institution) and Savara (fees paid to institution), Grant/research support from: Boehringer Ingelheim (fees paid to institution) and Hoffmann-La Roche (fees paid to institution), Vanessa Smith Speakers bureau: Boehringer Ingelheim and Janssen-Cilag NV, Consultant of: Boehringer Ingelheim, Grant/research support from: Belgian Fund for Scientific Research in Rheumatic diseases (FWRO), Boehringer Ingelheim, Janssen-Cilag NV and Research Foundation - Flanders (FWO), Dinesh Khanna Shareholder of: Eicos Sciences, Inc. (less than 5\%), Consultant of: Acceleron Pharma, Actelion,
AbbVie, Amgen, Bayer, Boehringer Ingelheim, CSL Behring, Corbus, Gilead Sciences, Galapagos NV, Genentech/Roche, GlaxoSmithKline, Horizon Therapeutics, Merck Sharp \& Dohme, Mitsubishi Tanabe Pharma, Sanofi-Aventis and United Therapeutics, Grant/research support from: Bayer, Bristol-Myers Squibb, Horizon Therapeutics, Immune Tolerance Network, National Institutes of Health and Pfizer, Employee of: Chief Medical Officer- CiviBioPharma/Eicos Sciences, Inc., Christopher Denton Speakers bureau: Boehringer Ingelheim Corbus, Janssen, and Mallinckrodt Pharmaceuticals, Consultant of: Acceleron Pharma, Arxx Therapeutics, Bayer, Boehringer Ingelheim, Corbus, CSL Behring, Galapagos NV, GlaxoSmithKline, Horizon Therapeutics, Janssen, Mallinckrodt Pharmaceuticals, Roche, Sanofi and UCB, Grant/research support from: Arxx Therapeutics, GlaxoSmithKline and Servier, Wim Wuyts: None declared Corinna Miede Employee of: Currently an employee of mainanalytics $\mathrm{GmbH}$, contracted by Boehringer Ingelheim, Margarida Alves Employee of: Currently an employee of Boehringer Ingelheim, Steven Sambevski Employee of: Currently an employee of Boehringer Ingelheim, Yannick Allanore Consultant of: Boehringe Ingelheim, Medsenic, Menarini and Sanofi, Grant/research support from: Alpine Pharmaceuticals

DOI: 10.1136/annrheumdis-2021-eular.834

\section{OP0171 \\ PHASE 3 TRIAL OF LENABASUM, A CB2 AGONIST, FOR THE TREATMENT OF DIFFUSE CUTANEOUS SYSTEMIC SCLEROSIS (DCSSC)}

R. Spiera ${ }^{1}$, M. Kuwana ${ }^{2}$, D. Khanna ${ }^{3}$, L. Hummers ${ }^{4}$, T. Frech ${ }^{5}$, W. Stevens ${ }^{6}$, J. Gordon ${ }^{7}$, S. Kafaja ${ }^{8}$, M. Matucci-Cerinic ${ }^{9}$, O. Distler ${ }^{10}$, E. B. Lee ${ }^{11}$, Y. Levy ${ }^{12}$ J. B. Jun ${ }^{13}$, S. Constantine ${ }^{14}$, N. Dgetluck ${ }^{14}$, B. White ${ }^{14}$, D. Furst ${ }^{8}$, C. Denton ${ }^{15}$. ${ }^{1}$ Hospital for Special Surgery, Department of Medicine, New York, United States of America; ${ }^{2}$ Nippon Medical School Graduate School of Medicine, Department of Allergy and Rheumatology, Tokyo, Japan; ${ }^{3}$ University of Michigan School of Medicine, Scleroderma Program, Ann Arbor, United States of America; ${ }^{4}$ Johns Hopkins University School of Medicine, Division of Rheumatology, Baltimore, United States of America; ${ }^{5}$ University of Utah, Division of Rheumatology, Salt Lake City, United States of America; ${ }^{6}$ St. Vincent's Hospital, Department of Rheumatology, Melbourne, Australia; ${ }^{7}$ Hospital for Special Surgery, Department of Rheumatology, New York, United States of America; ${ }^{8}$ David Geffen School of Medicine at University of California, Department of Rheumatology, Los Angeles, United States of America; ${ }^{9}$ University of Florence, Department of Experimental Rheumatology, Florence, Italy; ${ }^{10}$ University Hospital Zurich, Department of Rheumatology, Zurich, Switzerland; ${ }^{11}$ Seoul National University Hospital, Division of Rheumatology, Seoul, Korea, Rep. of (South Korea); ${ }^{12}$ Israel Sackler School of Medicine, Tel Aviv University, Department of Internal Medicine, Tel Aviv, Israel; ${ }^{13}$ Hanyang University Hospital for Rheumatic Diseases, Department of Rheumatology, Seoul, Korea, Rep. of (South Korea): ${ }^{14}$ Corbus Pharmaceuticals, Clinical, Norwood, United States of America; ${ }^{15}$ Royal Free Hospital, University College London, Division of Medicine, London, United Kingdom

Background: Lenabasum is an oral CB2 agonist that attenuates inflammation and fibrosis in SSc animal models and showed clinical benefit with acceptable safety in a Phase 2 trial in dcSSc.

Objectives: Test efficacy and safety of lenabasum in a Phase 3 trial in dcSSc. Methods: Subjects $\geq 18$ years old with disease duration $\leq 6$ years were randomized 1:1:1 to lenabasum $5 \mathrm{mg}, 20 \mathrm{mg}$, or placebo (PBO), all BID, with stable background immunosuppressant therapy (IST) allowed. The primary efficacy endpoint was ACR CRISS score, and secondary endpoints were $\Delta \mathrm{mRSS}$ $\triangle \mathrm{HAQ}-\mathrm{DI}$, and $\triangle \mathrm{FVC}$, all at Week 52 for lenabasum $20 \mathrm{mg}$ vs $\mathrm{PBO}$.

Results: 363 adults were dosed; $37(10 \%)$ stopped study drug early, with only 1 subject (PBO cohort) stopping due to adverse event (AE). Baseline demographics were similar among groups. Disease duration was $\leq 3$ years in $60 \%$ and $66 \%$, mean mRSS score was 22.0 and 23.3 , and background IST was used by $89 \%$ and $84 \%$ of lenabasum $20 \mathrm{mg}$ and PBO groups, respectively.

Safety results showed serious AEs and severe AEs occurred in $9.2 \%$ and $5.8 \%$ vs $14.6 \%$ and $13.0 \%$, respectively, of lenabasum $20 \mathrm{mg}$ and PBO groups. Efficacy results (Table) demonstrated:

No significant differences were seen in primary and secondary efficacy endpoints. Primary MMRM analyses with treatment-by-time-by-subgroup interactions showed that background mycophenolate (MMF) significantly influenced the outcome

- $\quad$ oSubjects on no IST with disease duration $\leq 3$ years were only $7 \%$ of PBO subjects and showed little improvement on PBO, in line with other dcSSc trials in which IST was restricted. Post-hoc subgroup analyses of these subjects on no IST suggested improvement in $\triangle \mathrm{mRSS}$ and $\triangle \mathrm{HAQ}-\mathrm{DI}$, for lenabasum $20 \mathrm{mg}$ vs PBO

uUnexpectedly high improvement occurred in PBO subjects receiving IST, notably those on MMF started within 2 years of baseline

nPost-hoc analyses of subjects on established IST (MMF or, if no MMF, $\geq 1$ non-MMF IST started $>2$ years before baseline 
Table 1. Primary and secondary efficacy endpoints and post-hoc analyses, Week 52

\begin{tabular}{|c|c|c|c|c|c|c|c|}
\hline Group, by IST treatment & Cohort & $\mathbf{N}$ & $\Delta \mathrm{mRSS}$, mean (SD) & $\Delta \mathrm{FVC} \%$ mean (SD) & $\Delta \mathrm{FVC}, \mathrm{mL}$ mean (SD) & $\triangle \mathrm{HAQ}-\mathrm{DI}$ mean (SD) & ACR CRISS median \\
\hline \multicolumn{8}{|c|}{ mITT population, MMRM primary analysis method } \\
\hline \multirow[t]{2}{*}{ All } & Placebo & 123 & $-8.1(7.72)$ & $-1.0(8.68)$ & $-51(317)$ & $-0.13(0.468)$ & 0.887 \\
\hline & Lenabasum $20 \mathrm{mg}$ & 120 & $-6.7(6.59)$ & $-1.6(6.91)$ & $-78(265)$ & $-0.13(0.436)$ & 0.888 \\
\hline \multicolumn{8}{|c|}{ Placebo subjects, per protocol completers, LOCF } \\
\hline No IST & Placebo & 16 & $-2.3(9.4)$ & $-2.8(7.4)$ & $-97(244)$ & $0.12(0.34)$ & 0.417 \\
\hline All IST & Placebo & 97 & $-8.9(7.07)$ & $-1.0(9.2)$ & $-43(330)$ & $-0.17(0.474)$ & 0.936 \\
\hline MMF, no other IST & Placebo & 29 & $-10.7(8.1)$ & $-0.58(7.1)$ & $-37(235)$ & $-0.12(0.456)$ & 0.935 \\
\hline MMF $\leq 2$ years, no other IST & Placebo & 23 & $-11.7(8.1)$ & $-0.3(6.0)$ & $-41(197)$ & $-0.13(0.495)$ & 0.935 \\
\hline Non-MMF $\leq 2$ years & Placebo & 24 & $-6.7(6.2)$ & $-1.4(7.87)$ & $-52(281)$ & $-0.15(0.357)$ & 0.931 \\
\hline \multicolumn{8}{|c|}{ Post-hoc comparisons, per protocol completers, LOCF } \\
\hline \multirow[t]{2}{*}{ No IST } & Placebo & 16 & $-2.3(9.4)$ & $-2.8(7.4)$ & $-97(244)$ & $0.12(0.34)$ & 0.417 \\
\hline & Lenabasum $20 \mathrm{mg}$ & 10 & $-6.3(6.02)$ & $-2.3(5.58)$ & $-99(209)$ & $-0.06(0.498)$ & 0.811 \\
\hline \multirow[t]{2}{*}{ Established IST1 } & Placebo & 26 & $-6.1(5.35)$ & $-4.6(10.11)$ & $-170(350)$ & $-0.17(0.445)$ & 0.619 \\
\hline & Lenabasum $20 \mathrm{mg}$ & 38 & $-7.4(5.08)$ & $0.4(5.70)^{2}$ & $-21(233)^{3}$ & $-0.07(0.357)$ & 0.941 \\
\hline \multirow[t]{2}{*}{ Established IST, subjects with ILD } & Placebo & 22 & $-5.9(5.28)$ & $-3.7(5.43)$ & $-133(206)$ & $-0.10(0.372)$ & 0.553 \\
\hline & Lenabasum $20 \mathrm{mg}$ & 33 & $-7.2(5.70)$ & $-1.0(10.5)$ & $-47(365)$ & $-0.06(0.391)$ & 0.819 \\
\hline
\end{tabular}

${ }^{2} \mathrm{P}=0.0386$ two-sample t-test; ${ }^{3} \mathrm{P}=0.0481$ two-sample t-test; other comparisons were not significant

suggested improvement in $\triangle \mathrm{FVC} \%$ (nominal $\mathrm{P}=0.0386$ ) and $\triangle \mathrm{FVC} \mathrm{mL}$ (nominal $\mathrm{P}=0.0481$ ) for lenabasum $20 \mathrm{mg}$ vs $\mathrm{PBO}$. Improvement in FVC was also seen in subjects on established IST who had ILD at baseline, lenabasum $20 \mathrm{mg}$ vs PBO mACR CRISS score demonstrated a ceiling effect and correlated most highly with $\triangle$ mRSS $(r=-0.739)$ and moderately with MDGA $(-0.432)$, HAQ-DI (-0.362), FVC\% (0.366), and PtGA (-0.288)

Conclusion: Lenabasum was safely used in this study. Unexpectedly high improvement on background IST, especially MMF, has not been previously reported at this level. The primary endpoint was not met. Post-hoc analyses showed greater improvement in lenabasum- vs PBO-treated subjects who were not on background IST and those on established IST, including subjects with ILD. Disclosure of Interests: Robert Spiera Consultant of: Abbvie, Roche-Genetech, GSK, CSL Behring, Sanofi, Janssen, Chemocentryx, Formation Biologics, Mitsubishi Tanabe, Grant/research support from: Roche-Genetech, GSK, Boehringer Ingelheim, Chemocentryx, Corbus, Formation Biologics, Sanofi, Inflarx, Astra Zeneca, Kadmon, Masataka Kuwana Speakers bureau: Boehringer-Ingelheim, Chugai, Janssen, Consultant of: Boehringer-Ingelheim, Chugai, Corbus, Grant/ research support from: Boehringer-Ingelheim, Chugai, MBL, Ono Pharmaceuticals, Tanabe-Mitsubishi, Dinesh Khanna Shareholder of: Eicos Sciences, Inc (less than 5\%). Leadership/Equity position - Chief Medical Officer, CiviBioPharma/Eicos Sciences, Inc, Consultant of: Acceleron, Actelion, Abbvie, Amgen, Bayer, Boehringer Ingelheim, CSL Behring, Corbus, Gilead, Galapagos, Genentech/Roche, GSK, Horizon, Merck, Mitsubishi Tanabe Pharma, Sanofi-Aventis, and United Therapeutics, Grant/research support from: NIH, Immune Tolerance Network, Bayer, BMS, Horizon, Pfizer, Laura Hummers Consultant of: CSL Behring, Boehringer Ingelheim, Grant/research support from: Investigator for study sponsored by Corbus Pharmaceuticals. Corbus, Boehringer Ingelheim, Medpace, Kadmon, Cumberland, CSL Behring, Tracy Frech Grant/research support from: Investigator for study sponsored by Corbus Pharmaceuticals, Wendy Stevens Grant/research support from: Investigator for study sponsored by Corbus Pharmaceuticals, Jessica Gordon Grant/research support from: Investigator for study sponsored by Corbus Pharmaceuticals. Research funding for EICOS Pharmaceuticals and Cumberland Pharmaceuticals., Suzanne Kafaja Grant/ research support from: Investigator for study sponsored by Corbus Pharmaceuticals, Marco Matucci-Cerinic Consultant of: Actelion, Janssen, Inventiva, Bayer, Biogen, Boehringer, CSL Behring, Corbus, Galapagos, Mitsubishi, Samsung, Regeneron, Acceleron, MSD, Chemomab, Lilly, Pfizer, Roche, Grant/research support from: Investigator for study sponsored by Corbus Pharmaceuticals, Oliver Distler Consultant of: Consultancy relationship and/or has received research funding in the area of potential treatments for systemic sclerosis and its complications from (last three years): Abbvie, Acceleron Pharma, Amgen, AnaMar, Arxx Therapeutics, Baecon Discovery, Blade Therapeutics, Bayer, Boehringer Ingelheim, ChemomAb, Corbus Pharmaceuticals, CSL Behring, Galapagos NV, Glenmark Pharmaceuticals, GSK, Horizon (Curzion) Pharmaceuticals, Inventiva, iQvia, Italfarmaco, iQone, Kymera Therapeutics, Lilly, Medac, Medscape, Mitsubishi Tanabe Pharma, MSD, Novartis, Pfizer, Roche, Sanofi, Serodapharm, Topadur, Target Bioscience and UCB., Eun Bong Lee Grant/research support from: Investigator for study sponsored by Corbus Pharmaceuticals, Yair Levy Grant/ research support from: Investigator for study sponsored by Corbus Pharmaceuticals, Jae-Bum Jun Consultant of: Consultant to Boehringer Ingelheim Korea, Jeil Pharma, Dae Woong Pharma, Kwangdong Pharma, and Sama Pharma., Grant/research support from: Investigator for study sponsored by Corbus Pharmaceuticals, Scott Constantine Employee of: Employee of Corbus Pharmaceuticals, Nancy Dgetluck Employee of: Employee of Corbus Pharmaceuticals, Barbara White Employee of: Employee and stockholder of Corbus Pharmaceuticals, Daniel Furst Consultant of: Corbus, Galapagos, Pfizer, CSL Behring, Mitsubishi Tanabi, Actelion, Amgen, Novartis, Roche/Genentech, Gilead, Talaris, and Boehringer Ingelheim., Grant/research support from: grants from Corbus,
Galapagos, GSK, Pfizer, Talaris, CSL Behring, Mitsubishi Tanabi, Christopher Denton Consultant of: Consultancy fees and/or honoraria from Corbus, Actelion, GlaxoSmithKline, Bayer, Sanofi, Galapagos, Inventiva, Boehringer Ingelheim, Roche, CSL Behring, Acceleron, Horizon, Arxx Therapeutics DOI: 10.1136/annrheumdis-2021-eular.1795

\section{OP0172 $\quad$ BRENTUXIMAB VEDONTIN FOR SKIN INVOLVEMENT IN REFRACTORY DIFFUSE CUTANEOUS SYSTEMIC SCLEROSIS, INTERIM RESULTS OF A PHASE IIB OPEN-LABEL TRIAL}

A. Fernandez-Codina ${ }^{1,2,3}$, T. Nevskaya ${ }^{1}$, J. Pope ${ }^{1} .{ }^{1}$ Western University, Medicine, Rheumatology division, London, Canada; ${ }^{2}$ Windsor Regional Hospital Ouellette Campus, Medicine, Windsor, Canada; ${ }^{3}$ Hospital Clínic de Barcelona, Systemic Autoimmune Diseases, Barcelona, Spain

Background: Systemic sclerosis (SSc) is an autoimmune disease affecting multiple organs causing morbidity and mortality. Treatments targeting SSc skin often have limited success. The presence of CD30+ lymphocytes in skin biopsies and increased levels of serum CD30 have been reported in SSc patients ${ }^{1}$. This could constitute a new therapeutic target.

Objectives: To explore the efficacy and safety of brentuximab vedotin, a chimeric anti-CD30 antibody drug conjugate, in patients with severe active diffuse cutaneous SSc who failed multiple treatments.

Methods: This Phase Ilb, single center, open-label, investigator-initiated trial will recruit 10 patients. Brentuximab vedotin $0.6 \mathrm{mg} / \mathrm{Kg}$ was infused intravenously every 3 weeks for 48 weeks. Inclusion criteria were age $\geq 18$ years, meeting the 2013 ACR/EULAR SSc classification criteria, modified Rodnan skin score (mRSS) $\geq 15$ with $<5$ years since the first non-Raynaud's symptom and/or skin worsening despite immunosuppression. Patients were allowed to continue their standard of care medications for SSc except for rituximab. Patients with severe cardiac or pulmonary SSc involvement, severe infections, significant peripheral neuropathy, or active malignancy were excluded. The primary objective was a decrease in mRSS of $\geq 8$ at 48 weeks. The main secondary endpoint was MRSS at 24 weeks. Differences were assessed by paired t tests. Data were compared to 16 age, disease duration, mRSS and past/present use of immunosuppressors-matched controls (ratio 2-3:1) from the Canadian Scleroderma Research Group (CSRG) registry. Results: Eight of 10 patients have been recruited to date; two are in the first 8 weeks and one was withdrawn at her request after developing influenza at week 12. Five subjects ( $60 \%$ female) have reached week 24 , and 3 have completed 48 weeks. The mRSS is shown in Table 1. The $\triangle \mathrm{MRSS}$ for patients treated with brentuximab between weeks 0 and 24 was $8.2([\mathrm{Cl} 95 \% 2.8,13.6], \mathrm{p}=0.013)$ and from 0 to 48 was 15.3 ([Cl $95 \% 8.2,22.5], \mathrm{p}=0.012)$. Whereas, the $\Delta$ MRSS for the CSRG controls was 3.1 ([Cl 95\% -2, 8.2], $\mathrm{p}=0.211)$ at 48 weeks. Assuming that mRSS would at least be the same from week 24 to 48 in the 2 cases who are between 24 and 48 weeks with brentuximab, we compared the 5 cases vs controls (Figure 1). $\Delta$ MRSS for Brentuximab was 12.2 ([Cl 95\% 5.9, 18.5], $p=0.006$ No cases have developed a peripheral neuropathy and only one SAE (influenza).

Table 1.

\begin{tabular}{|c|c|c|c|c|c|c|c|}
\hline N (SD) & $\mathbf{N}$ & Age & $\begin{array}{l}\text { Disease } \\
\text { duration }\end{array}$ & $\begin{array}{l}\text { mRSS } \\
\text { week } 0\end{array}$ & $\begin{array}{c}\text { mRSS } \\
\text { week } 24\end{array}$ & $\begin{array}{c}\text { mRSS } \\
\text { week } 48\end{array}$ & $\begin{array}{c}\text { mRSS } \\
\text { week } 48^{\star \star}\end{array}$ \\
\hline Case & 5 & $60.2(9.3)$ & $4.5(2.1)$ & $33(5.2)$ & $24.8(6)$ & 15.7 (3) & $20.8(8.3)$ \\
\hline Control & 16 & $58.5(8.3)$ & $4.9(2.1)$ & $31.3(5.9)$ & $\mathrm{N} / \mathrm{D}$ & $28.1(7.5)$ & $28.1(7.5)$ \\
\hline p & & 0.731 & 0.775 & 0.559 & N/D & 0.013 & 0.079 \\
\hline
\end{tabular}

mRSS $=$ modified Rodnan skin score, N/D = no data, ${ }^{\star \star}{ }^{*}=$ comparisons including 5 cases, assuming stability in MRSS from week 24 to 48 in cases 5 and 6 